\title{
The Augmented Reality Application of Multimedia Technology in Aquatic Organisms Instruction
}

\author{
Chih-Hsiao Tsai ${ }^{*}$, Jung-Chuan Yen ${ }^{2}$ \\ ${ }^{1}$ Information Technology, Takming University of Science and Technology, Taipei, Chinese Taipei \\ ${ }^{2}$ Mathematics and Information Education, National Taipei University of Education, Taipei, Chinese Taipei \\ Email: ${ }^{*}$ chtsai2104@gmail.com, Icyan2003@gmail.com
}

Received 25 May 2014; revised 20 June 2014; accepted 18 July 2014

Copyright (C) 2014 by authors and Scientific Research Publishing Inc.

This work is licensed under the Creative Commons Attribution International License (CC BY). http://creativecommons.org/licenses/by/4.0/

(c) $\underset{\mathrm{EY}}{\mathrm{B}}$ Open Access

\begin{abstract}
The paper elaborates the features and superiority of applying multimedia technology to aquatic organisms in a Science and Life Technology course. The augmented reality application of multimedia technology in aquatic organisms' instruction has its own features, teaching information capacity, interactive user interface. The paper concludes the superiority of Unity and Vuforia AR instruction from five perspectives; meanwhile, the paper elaborates its disadvantages. An AR-based instruction attitude questionnaire was conducted at the end of the experiment to obtain learners' perspectives of the system. Learners in AR approach demonstrate higher motivation and concentrate their attention on the learning tasks. Learners showed more positive attitude in willingness to use the AR-based instruction to improve learning interests. This study provided insights for better understanding the design, theory and practice of e-learning through augmented reality technology.
\end{abstract}

\section{Keywords}

Unity and Vuforia AR, Multimedia Technology, Augmented Reality, Aquatic Organisms, Attitude Questionnaire

\section{Introduction}

Augmented reality (AR) has been applied in various fields, including military training, education, engineering, industrial design, arts, and entertainment [1] [2]. Multimedia computer-assisted instruction motivates learning,

\footnotetext{
${ }^{*}$ Corresponding author.
}

How to cite this paper: Tsai, C.-H. and Yen, J.-C. (2014) The Augmented Reality Application of Multimedia Technology in Aquatic Organisms Instruction. Journal of Software Engineering and Applications, 7, 745-755. 
reduces learning time, and improves learning efficiency [3]. Reference [4] found that multimedia better enabled learners to express themselves, encouraged the desire for self-learning, and increased interactions between instructors and learners. In addition, various experiments have shown that obtaining operating experience is vital; however, simulation software enables learners to practice [5] and reduces the risk factors of conducting experiments. Reference [6] stated that presenting abstract material using multimedia enabled learners to understand the material better, audio and visual displays allowed learners to interact with the material. Courses that employ AR foster motivation and result in better learning achievements [7] [8].

Reference [5] highlighted that visualizing abstract ideas facilitated learners' understanding by reinforcing the abstract ideas throughout the courses, which enabled learners to observe and gain experience in a limited period. Reference [9] stated that employing AR enabled learners, in both virtual and real environments, to interact with virtual objects smoothly, thereby generating new teaching, and learning strategies that could be implemented regardless of learners' prior experience with computers. Reference [10] suggested that AR fosters stronger motivation than static images, enabling learners to capture the essence of the subjects without the limitations of reading text or observing images.

Therefore, this study presents a way to employ AR technology to create teaching models to learn aquatic organisms. AR is used to reinforce learners' understanding of the typology and features of an aquatic organism. It is expected that it will increase learners' interests and encourage them to learn more on the concept.

\section{Literature Review}

\subsection{Computer-Assisted Instruction}

Computer-assisted instruction refers to design a learning system with information technology depends on learners' ability and self-efficacy levels [11] [12]. Learners choose topics according to their individual preferences, perform self-evaluations, and receive immediate feedback. In addition, learners using computer-assisted instruction have a higher likelihood of interacting with their instructors. Multimedia visualizes abstract materials to foster learning achievements and interests. To ensure completeness, instructors may add relevant information to the materials. The additional information is beneficial to learners attempting to understand the material [6] [13]. Teaching efficiency may improve if computer-assisted instruction supplements expository instruction and presents abstract materials using computers, images, audio and visual effects, and games. It is because it enables learners to store information in their long-term memory and improves their learning efficiency. The computer course designers are the key factors responsible for the process of teaching [14].

\subsection{Augmented Reality}

\subsubsection{The Definition of AR}

AR is an extension of virtual reality (VR). Scenes and existing objects are presented virtually in VR applications, whereas in AR applications, information or virtual objects are presented in actual scenes after computation [15]. Reference [16] considered real and virtual situations to be two ends of a continuum; they explored the possibility of operating with computers, categorized the application environments to establish a theoretical foundation, and summarized the theory. AR combines virtual materials with the real scene and display the virtual materials generated by computers. Reference [17] [18] stated that AR creates a situation that cannot be presented virtually. AR has three essential properties. First, virtual objects are combined with real environment. Second, immediate interaction is facilitated. Third, AR operates in a 3D environment.

\subsubsection{The Presentation of AR}

AR has distinct requirements based on varied environments or conditions. Reference [16] defined two methods of displaying AR. First, monitor-based AR, where all the scenes are outputted by a projector or monitor, is the simplest means of display and has the lowest hardware requirements. Second, AR may be implemented with a head-mounted see-through video, which requires a head-mounted display panel capable of capturing and localizing external images. Images are displayed on the head-mounted display panel after they are created by superimposing images generated by the computer. This study adopts monitor-based AR and employs the convenience of webcams; thus, the proposed method is simple to use under any circumstances. Equipment costs are minimal and the setup is simple, allowing AR to be a feasible tool in learning environments. 


\subsubsection{The Advantages of Applying AR in Education}

- Interactions: AR is simple for learners to use and promote discussions with other learners, thereby enhancing their motivation to learn through new experiences.

- Perceptual feedback: learners can operate AR at their own paces to obtain immediate feedback in virtual 3D object modeling.

- Spatial relationships: by using these applications, learners may effortlessly understand the spatial relationships between virtual objects, real objects, and real environments.

- Novel learning experiences: AR teaching uses new multimedia technology and presents diversified multimedia content through the system, which allows learners to acquire knowledge of concepts and increases their interest in learning.

Therefore, this study develops materials that employ AR to facilitate learning. The reasons for employing AR when designing materials include the following: 1) motivating learners by employing multimedia; 2) designing virtual characters and environments; 3 ) improving understanding of the materials presented in the courses; and 4) facilitating learning efficiency through interaction.

\section{System Development}

\subsection{Teaching Materials}

To develop course material using AR, animals and plants from different aquatic environments were surveyed, the bodies of the aquatic organisms were examined, and the characteristics of their bodies and movements were depicted. This study specifies the physical characteristics and movements of aquatic organisms and focuses on how to improve their living environments and maintain their health. By employing AR and a zoom function to present the movements of aquatic plants and animals, learners observed the body parts of them and learned their functions.

\subsection{Planning and Developing the System}

This study was conducted in two stages. In the first stage, the AR system and the teaching materials were developed, and during the second stage, a teaching experiment was conducted. Software such as $3 \mathrm{ds}$ max, maya, photoshop, unity and android were used to implement the AR system. Figure 1 shows the system development tools.

\subsection{Developing the 3D Models of Aquatic Organisms}

Figure 2 shows the construction of the virtual aquatic organisms. During the modeling process, the number of surfaces of the model is minimized to accelerate computation and execution. Figure 3 shows that close observation of aquatic animals requires a greater number of surfaces to ensure that the models appear similar to existing aquatic animals. After the models are completed, the skeletal structure is used to represent the anatomy (e.g., fins, trunk, and appendages) of the aquatic animals in Maya to simulate the effect of movement. The system designed four models to give learners a selection of systems to observe the properties of the aquatic plants.

This system used unity to develop the teaching materials. We create an account with the Target Manager to get started creating and evaluating target images on Qualcomm Vuforia developer portal. The Target Manager is a web based tool for creating and managing targets (as shown in Figure 4). Target picture must have obvious features, distinctive lines. The number of buttons on the target is adjusted based on the teaching materials. When designing the target, the buttons were set at convenient locations, and the button sizes were matched to standard finger sizes. An augmentable rating determines the detection and tracking of the images. In addition, buttons could not overlap other buttons because the system would fail to correctly recognize which button was pressed. Figure 5 shows the development process and installation.

When describing the virtual objects, relevant information was presented in the text at the bottom of the monitor for learners' reference, as shown in Figure 6.

\subsection{Unity Software}

Unity is a game design engine that makes multiplatform deployment smooth and efficient. It comprises a graph- 


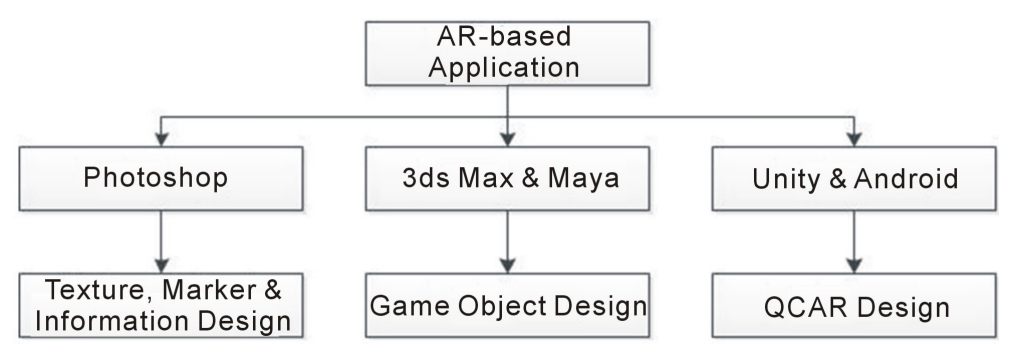

Figure 1. System development tools.

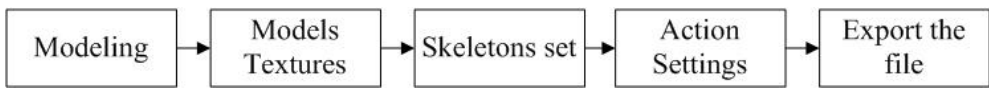

Figure 2. Model production process.
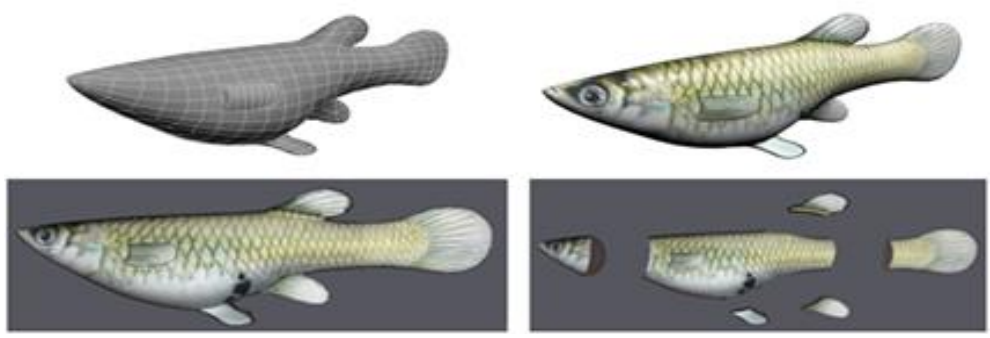

Figure 3. Model textures.

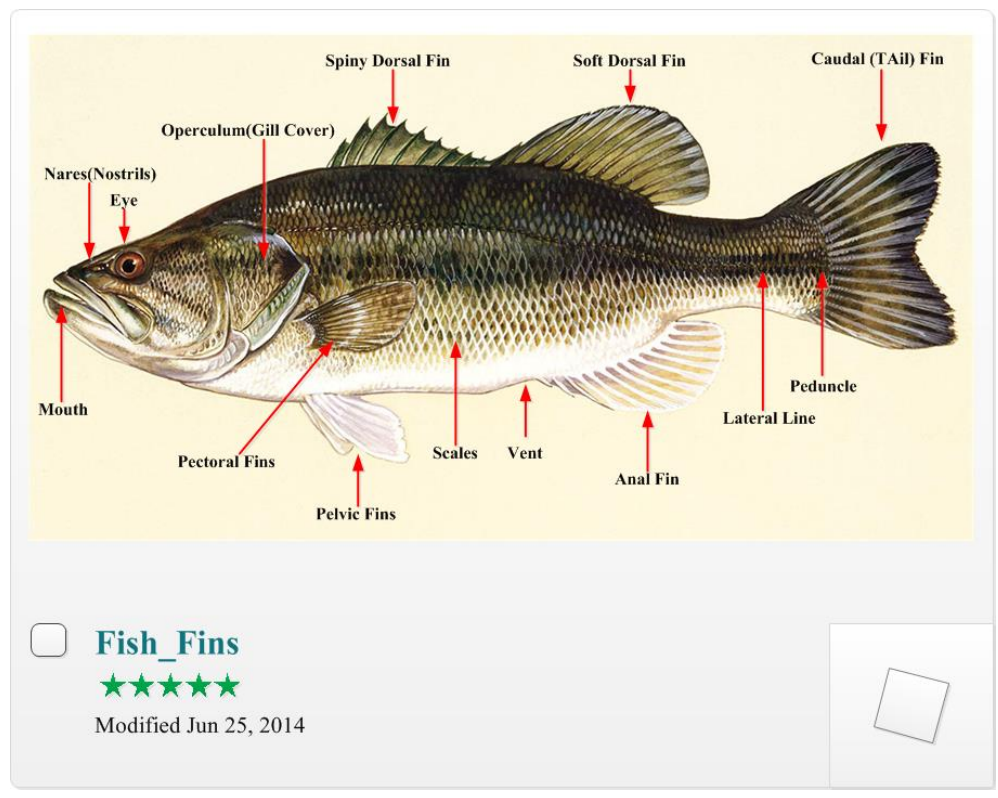

Figure 4. Upload target picture to Target Manager.

ical integrated development environment (as shown in Figure 7), high quality games and interactive content, and powerful rendering engine to develop games and seamlessly deploy to PC, Mac, Linux desktop, the Web, iOS, Android, PS4, Xbox One and other gaming consoles. Unity provides much documentation, projects and tutorials to help users decrease the time required for game design, reduce the complexity and cost of our efforts.

\subsubsection{Constructing the System Using Unity}

In this study, the system interactions were designed according to the required functions to satisfy learners' 


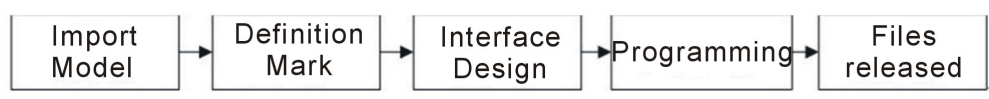

(a)

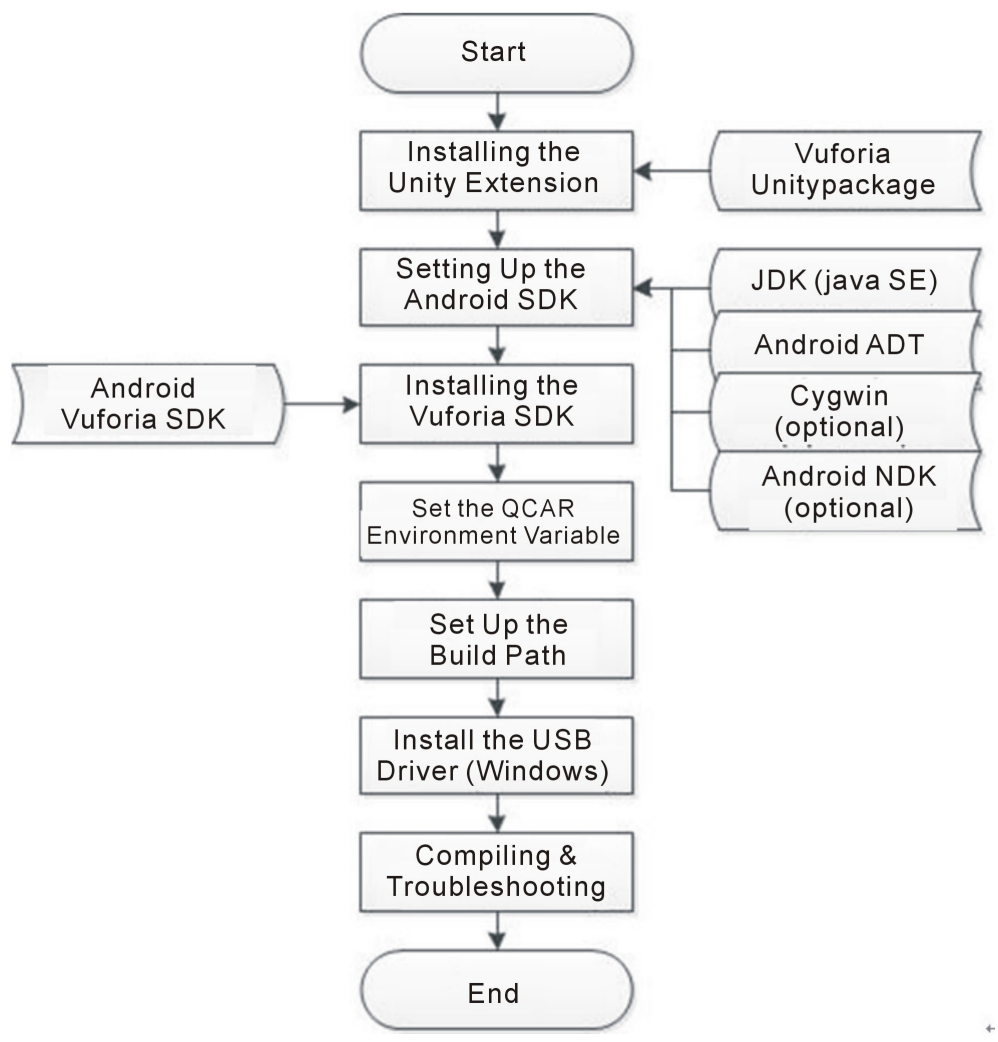

(b)

Figure 5. (a) Unity production process; (b) Development environment set up.

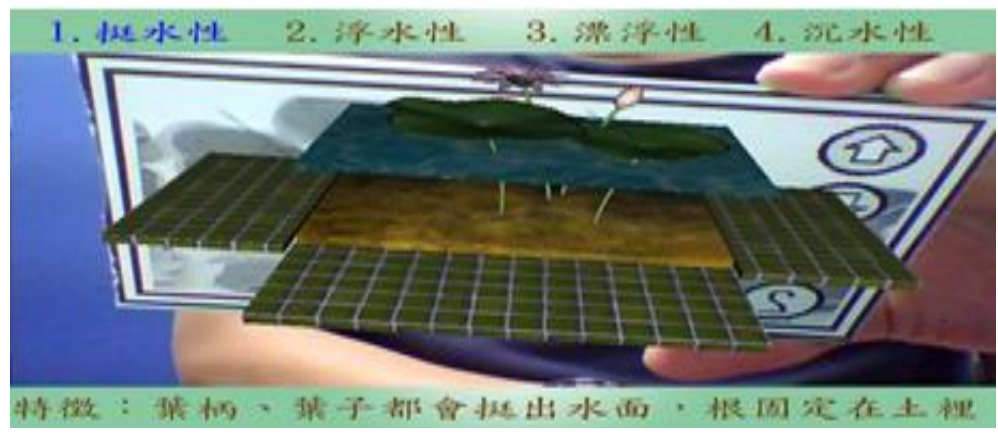

Figure 6. Operation interface example.

learning and observation needs. The Vuforia SDK (as shown in Figure 8) provides many resources for unity, such as camera, image converter, tracker, application code, video background renderer, device databases and user-defined targets. Figure 9 provides an overview of the application development process with the Vuforiaplatform. The platform consists of the Vuforia Engine, the Target Management System hosted on the developer portal.

We upload the input image for the target that we want to track. The target resources can then be accessed by the device. The workflow (as shown in Figure 10) of our development shows in the following: First, we should open the Target Manager web and download the targets in unity editor format to match our development option. Then, we import the targets unity package into unity project; arrange the targets in a scene, and put virtual but- 


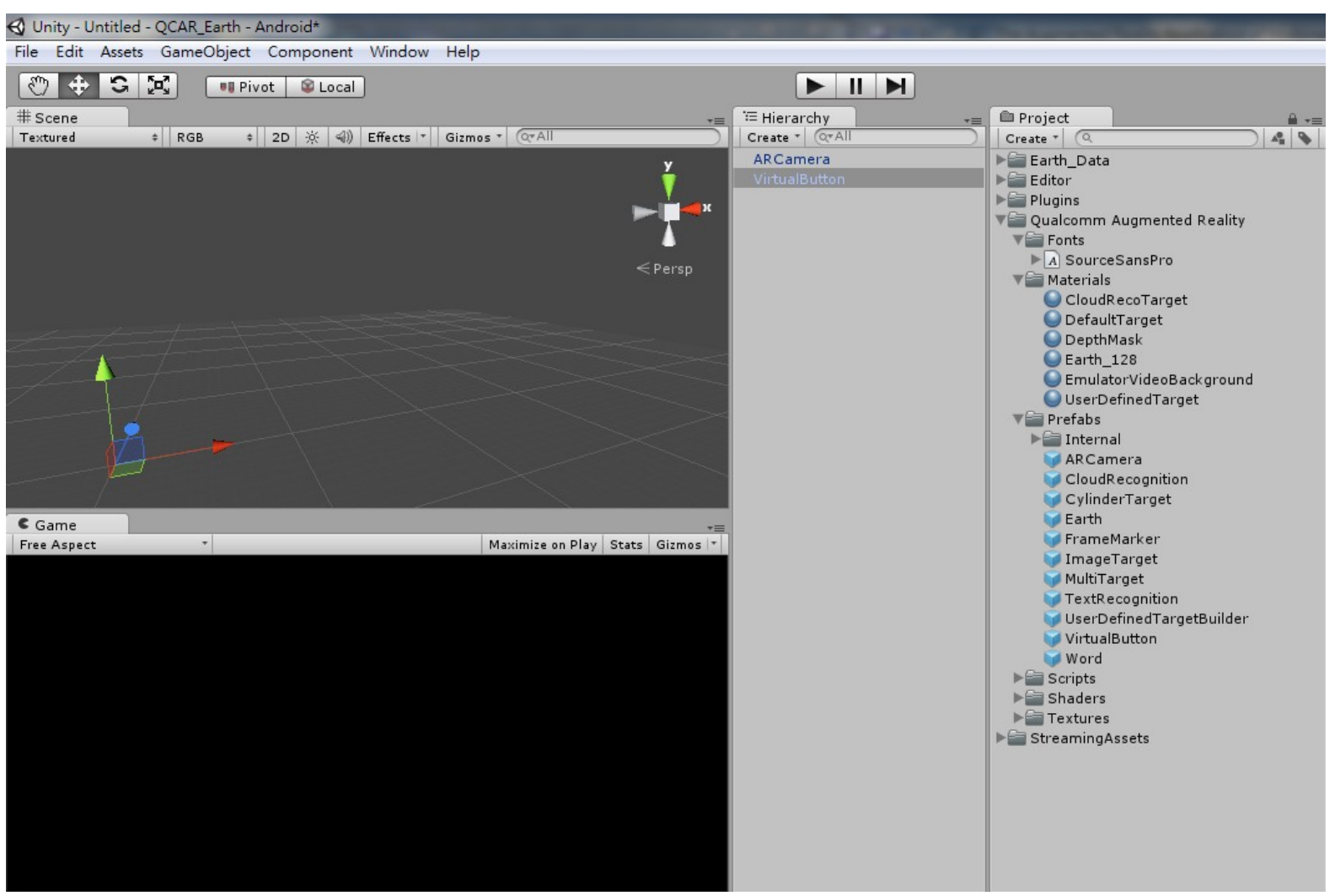

Figure 7. Unity integrated development environment.

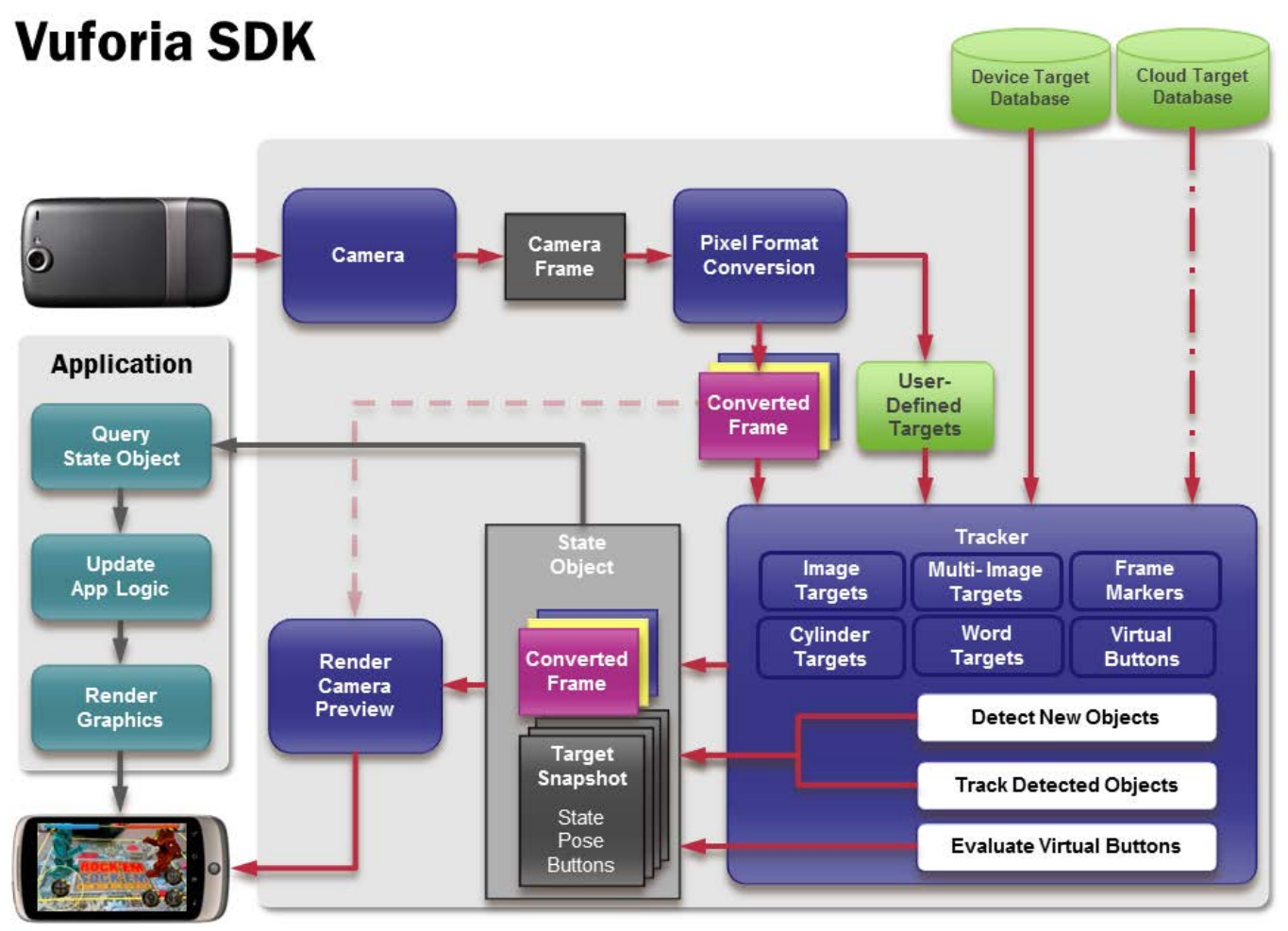

Figure 8. Data flow diagram of the Vuforia SDK. 


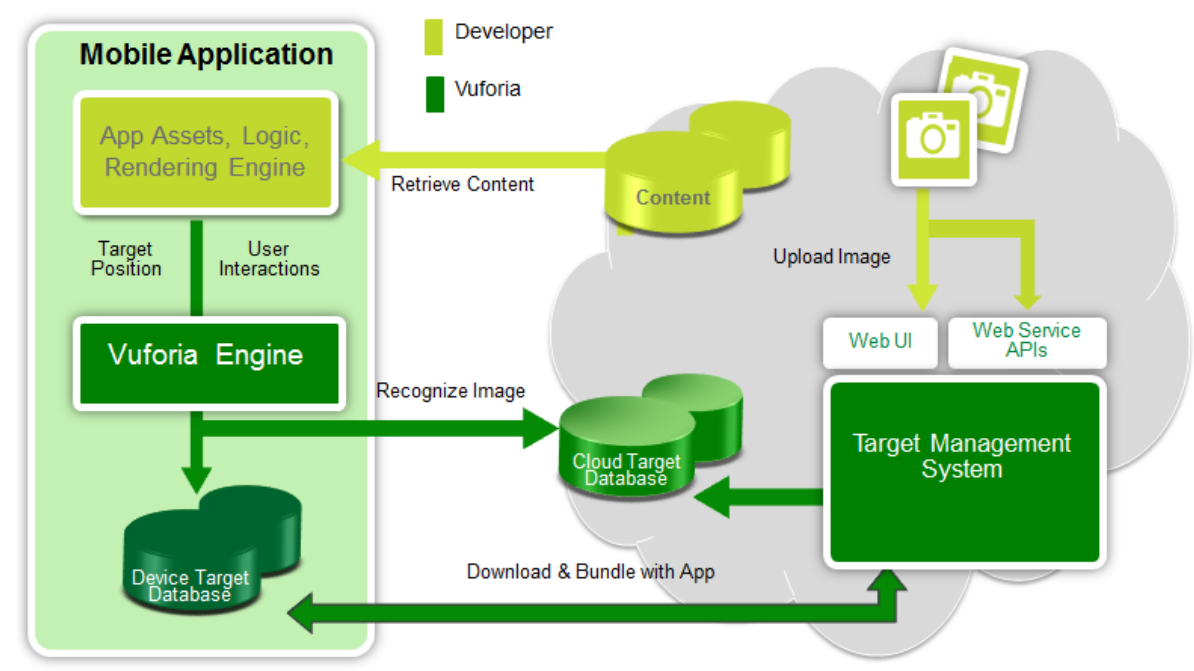

Figure 9. Data flow diagram of the development process.

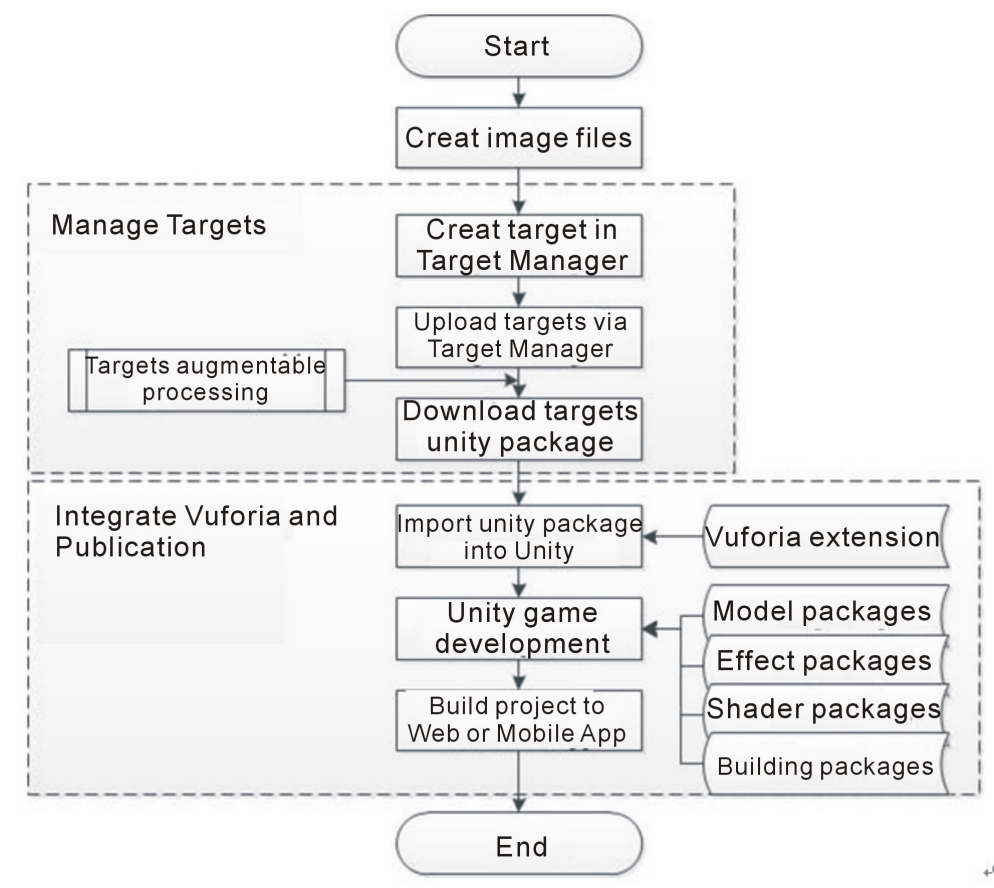

Figure 10. The workflow of our development.

tons and game objects in the targets. In addition, the Inspector panel of unity was used to adjust object settings, configure the component attributes, public variables value, and the relationship between objects. Finally, the teaching materials employing AR were presented as Web pages and also operate in mobile mode, enabling exportation to smart phones or tablets.

\subsubsection{Experimental Design and Subjects}

The subjects were 114 students from the University of Technology in northern Taiwan taking information technology and science courses. After the lesson, to further improve the system, an attitude questionnaire was distributed among the learners to understand students' attitudes and opinions of the teaching materials employing AR. The research tools used in this study are described below:

- The instruction materials developed by this study employing AR for the unit “aquatic organism”: The mate- 
rials were used to present the content of the unit. Learners were allowed to manipulate the picture cards to understand the knowledge related to them.

- The slides developed by this study for teaching the unit "aquatic organism".

- Attitude questionnaire: The attitude questionnaire used the Likert Scale to analyze students' feelings and attitudes toward using the system. The questionnaire included questions on the content of the teaching materials, interface design, multimedia features, interactive functions, and practicality. The attitude questionnaire is an effective and time-conserving approach to evaluate students' satisfaction with the system.

Computers were used to develop the teaching materials employing AR in this study. The duration of the lesson was 70 minutes. Students were seated in seats arranged by the instructor and provided information on the course. After the instruction, learners also required to complete the attitude questionnaire to obtain learners' opinions of employing augmented reality in teaching. The teaching was video recorded and photographed to record any teaching or learning issues and for making later observations of the class.

\section{Evaluation Results}

\subsection{Most Learners Show Positive Attitude on Helpfulness toward AR Learning System}

The object of the attitude questionnaire is for learners to estimate subjective feelings and their degree of satisfaction with regard to the system. The questionnaire has 15 questions and used a 5-point Likert scale, ranging from 1 , meaning strongly disagree, to 5 , meaning strongly agree. The questionnaire was divided into five aspects, with each aspect presenting three questions. Subjects finished operating the system and filled out the attitude questionnaire. Learners showed positive attitude $(\mathrm{M}=4.38)$ toward five aspects. We discussed with the learners about their ideas on the assisted learning system after they finished using the system and had filled out the attitude questionnaire. The learners agreed that the assisted learning system increased their interest in the concepts and encouraged them to learn more.

\subsection{Attitude Questionnaire Results}

\subsubsection{Teaching Materials}

Listed in Table 1 are the mean scores with regard to the aspect of teaching materials. The average score was 4.44, it indicates that most of the learners agree that AR assisted instruction materials is lively and interesting, help to understand the structure of aquatic organism, and can be used in other disciples teaching.

\subsubsection{Interface Design}

Listed in Table 2 are the mean scores with regard to the aspect of interface design. The average score was 4.42, it indicates that most of the learners agree that AR assisted instruction interface design is easy to operation. However, according to our observation, it's found that learners occasionally place the marker too close or too far, even left the marker outside the camera's detecting area. In addition, learners touch more than one button in the marker that then made system difficult to display correct object.

\subsubsection{Multimedia Features}

Listed in Table 3 are the mean scores with regard to the aspect of multimedia features. The average score was 4.38, it indicates that most of the learners agree that AR assisted instruction relatively easy to observe the movement of aquatic organism, is more realistic than the static images. They were quite satisfied with the multimedia features of the learning system.

\subsubsection{Interactive Functions}

Listed in Table 4 are the mean scores with regard to the aspect of interactive functions. The average score was 4.38, it indicates that most of the learners agree that the trigger animation when interact with the AR assisted instruction is very interesting. However, they think the amplify function cannot help them more clearly observe the fish parts.

\subsubsection{Practicability}

Listed in Table 5 are the mean scores with regard to the aspect of practicability. The average score was 4.32, it indicates that most of the learners agree that AR assisted instruction is practicability and helpful to learn the 
Table 1. The teaching materials aspect and the statistics for each question.

\begin{tabular}{l} 
Questions \\
\hline 1) I think the "augmented reality assisted instruction” materials lively and interesting. \\
2) I think the "augmented reality assisted instruction” materials help to understand the structure of \\
aquatic organism. \\
3) I think the presentation of "augmented reality assisted instruction" materials can be used in \\
other disciples teaching.
\end{tabular}

\section{Table 2. The interface design aspect and the statistics for each question.}

\begin{tabular}{l} 
Questions \\
\hline 4) I think the "augmented reality assisted instruction" design is lively and interesting. \\
5) I think the "augmented reality assisted instruction" using marker to interact with materials is \\
more interesting than static images. \\
6) I think the "augmented reality assisted instruction” can articulate express the various features of \\
aquatic organism.
\end{tabular}

Table 3. The multimedia features aspect and the statistics for each question.

Questions
7) I think the "augmented reality assisted instruction" relatively easy to observe the movement of
aquatic organism.
8) I think the "augmented reality assisted instruction" can help me quickly understand the knowledge
of the aquatic organism.
9) Through any point to observe aquatic organism, the "augmented reality assisted instruction" is
more realistic than the static images.

Table 4. The interactive functions aspect and the statistics for each question.

Questions
10) I think the function of "augmented reality assisted instruction" to separate the body structure of
fish is very cool.
11) I think the amplify function of "augmented reality assisted instruction” can be more clearly
observe the fish parts.
12) I think that the trigger animation when interact with the "augmented reality assisted instruction"
is very interesting.

\section{Table 5. The practicability aspect and the statistics for each question.}

\begin{tabular}{|c|c|c|}
\hline Questions & Mean & Avg \\
\hline $\begin{array}{l}\text { 13) I think using "augmented reality assisted instruction" will allow me to participate more } \\
\text { actively in the course. }\end{array}$ & 4.22 & \\
\hline 14) I think I would be willing to use "augmented reality assisted instruction” again. & 4.33 & 4.32 \\
\hline $\begin{array}{l}\text { 15) When learning the knowledge of aquatic organism, I think the "augmented reality assisted } \\
\text { instruction" is helpful. }\end{array}$ & 4.40 & \\
\hline
\end{tabular}

content knowledge. But, some learners cannot operate system successfully that make them feel less actively to participate in the course.

\subsection{Summary}

Some learners describe their feelings to help us to synthesize useful information. The following were a summary of the feedback created from learners that may affect satisfaction with the system:

- The amplification function of AR-assisted instruction did not allow learners to clearly observe all aspects of the fish. Learners commented that the close-ups of the fish should be more detailed.

- The distance between the markers and camera is difficult to control. The components did not display proper- 
ly because of the angles and distance.

- Learners need the support of a technical assistant. Some learners did not understand how to operate the markers and system. Teaching documents or assistants should be provided to assist them.

\section{Conclusion}

This study proposed an assisted learning system of the aquatic organism by using Unity and Vuforia AR technology. The experimental results show that it helped improve learning achievements. Most of the learners appreciated the teaching materials employing AR and considered the interactive functions straightforward to use. The majority of learners agree that AR teaching materials can enhance motivation in learning, the teaching materials design is lively and interesting, and it can be helpful for learning natural science. In addition, it can be used in other disciplines teaching. Future research should focus on learners' behavior analysis and system improvements. A number of learners reported that the teaching material employing AR was slow during interactive operations. The buttons should be clearly defined, the unit knowledge should be highlighted, the markers should be appropriately sized, and proper instructions should be provided to ensure that the learners are more focused on learning the material presented in the lesson.

\section{Acknowledgements}

The funding of this study was supported by the Ministry of Science and Technology of Taiwan under grant NSC 100-2511-S-147-002-MY3 and NSC 101-2511-S-147-001-.

\section{References}

[1] Azuma, R., Baillot, Y. and Behringer, R. (2001) Recent Advances in Augmented Reality. IEEE Computers and Graphic, 21, 34-47. http://dl.acm.org/citation.cfm?id=618862

[2] Lin, H.C.K., Hsieh, M.C., Liu, E.Z.F. and Chuang, T.Y. (2012) Interacting with Visual Poems through AR-Based Digital Artwork. Turkish Online Journal of Educational Technology, 11, 123-137. http://www.tojet.net/articles/v11i1/11111.pdf .

[3] Ma, H.L. and Wu, D.B. (1998) The Computer and Multimedia Technologies in Education. Ling-Tung Journal, 8, 432448.

[4] Chang, Y.L. (1995) Toward a Multi-Media-Oriented Demonstration of EFL Methodologies. Kaohsiung Normal University Journal, 6, 261-286.

[5] Chang, K.E., Chen, Y.L., Lin, H.Y. and Sung, Y.T. (2008) Effects of Learning Support in Simulation-Based Physics Learning. Computers \& Education, 51, 1486-1498. http://dx.doi.org/10.1016/j.compedu.2008.01.007

[6] Lu, C.C. and Yao, N.D. (2002) The Application and Introspection of Information Education in Elementary-School Curriculum. Elementary Education, 42, 19-24.

[7] Chen, C.H., Wu, F.G. and Zhung, S.K. (2006) Design and Augmented Reality Teaching System with Concept Mapping Technique. Proceedings of the 53rd Annual Conference of JSSD, Ishikawa, 30 June-2 July 2006, 250-251.

[8] Lin, H.C.K., Hsieh, M.C., Wang, C.H., Sie, Z.Y. and Chang, S.H. (2011) Establishment and Usability Evaluation of an Interactive AR Learning System on Conservation of Fish. Turkish Online Journal of Educational Technology, 10, 181187. http://www.tojet.net/articles/v10i4/10418.pdf

[9] Billinghurst, M. (2003) Augmented Reality in Education. http://www.solomonalexis.com/downloads/ar_edu.pdf

[10] Lin, S.H. (2009) The Influence of Infusing Augmented Reality into Mobile Learning on Elementary School Students' Learning Motivation and Achievement in Science and Technology. Master's Thesis, National University of Tainan, Taiwan.

[11] Chang, C.Y. and Lee, G. (2010) A Major E-Learning Project to Renovate Science Learning Environment in Taiwan. Turkish Online Journal of Educational Technology, 9, 7-12. http://www.tojet.net/articles/v9i1/911.pdf

[12] Isman, A. and Celikli, G.E. (2009) How Does Student Ability and Self-Efficacy Affect the Usage of Computer Technology? Turkish Online Journal of Educational Technology, 8, 33-38. http://www.tojet.net/articles/v8i1/814.pdf

[13] Bull, P.H. (2013) Cognitive Constructivist Theory of Multimedia: Designing Teacher-Made Interactive Digital. Creative Education, 4, 614-619. http://www.scirp.org/journal/PaperInformation.aspx?PaperID=36779

[14] Chen, D., Chen, X. and Gao, W. (2013) The Application and Perspective of Multimedia Technology in Chemistry Experimental Instruction in China. Creative Education, 4, 241-247.

http://www.scirp.org/journal/PaperInformation.aspx?paperID=29722 
[15] Liarokapis, F. (2007) An Augmented Reality Interface for Visualizing and Interacting with Virtual Content. Journal Virtual Reality, 11, 23-43. http://dx.doi.org/10.1007/s10055-006-0055-1

[16] Milgram, P. and Kishino, F. (1994) A Taxonomy of Mixed Reality Visual Displays. IEICE Transactions on Information and Systems, E77-D, 1321-1329. http://citeseerx.ist.psu.edu/viewdoc/summary?doi=10.1.1.102.4646

[17] Azuma, R. (1997) A Survey of Augmented Reality. Presence: Teleoperators and Virtual Environment, 6, 355-385.

[18] Qualcomm Vuforia (2011) Developer Portal. https://developer.vuforia.com/resources/dev-guide/ 
Scientific Research Publishing (SCIRP) is one of the largest Open Access journal publishers. It is currently publishing more than 200 open access, online, peer-reviewed journals covering a wide range of academic disciplines. SCIRP serves the worldwide academic communities and contributes to the progress and application of science with its publication.

Other selected journals from SCIRP are listed as below. Submit your manuscript to us via either submit@scirp.org or Online Submission Portal.
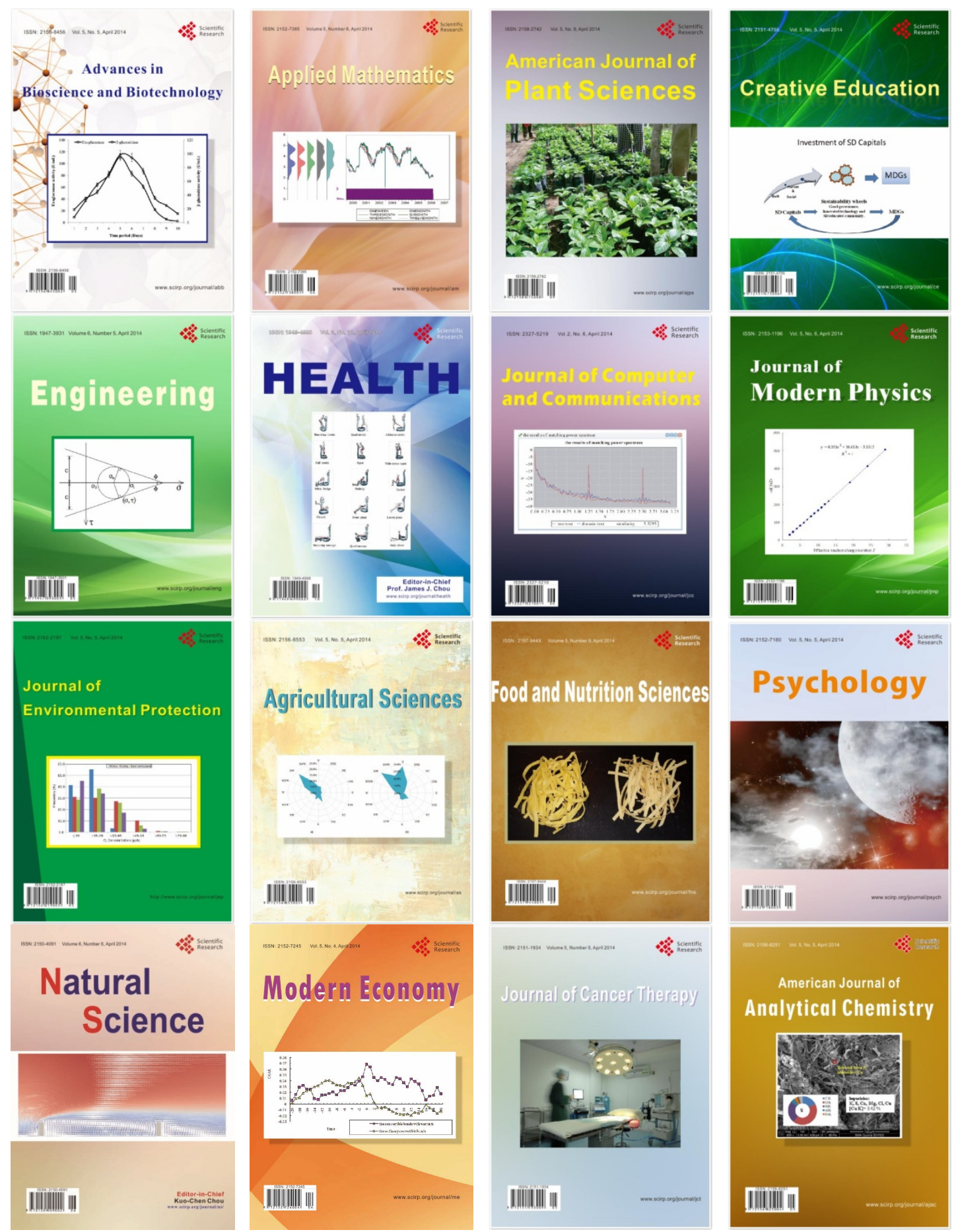